\title{
Influence of surface strain on activity and selectivity of Pd-based catalysts for the hydrogenation of acetylene: A DFT study
}

\author{
Ping Wang, Bo Yang * \\ School of Physical Science and Technology, ShanghaiTech University, Shanghai 201210, China
}

\section{A R T I C L E I N F}

\section{Article history:}

Received 1 March 2018

Accepted 7 April 2018

Published 5 September 2018

\section{Keywords:}

Surface strain

Pd

Acetylene hydrogenation

Selectivity

Activity

Subsurface

Density functional theory

Microkinetic modelling

\begin{abstract}
A B S T R A C T
The effects of surface strain and subsurface promoters, which are both important factors in heterogeneous catalysis, on catalytic selectivity and activity of Pd are examined in this study by considering the selective hydrogenation of acetylene as an example. Combined density functional theory calculations and microkinetic modeling reveal that the selectivity and activity of the Pd catalyst for acetylene hydrogenation can both be substantially influenced by the effects of Pd lattice strain variation and subsurface carbon species formation on the adsorption properties of the reactants and products. It is found that the adsorption energies of the reactants and products are, in general, linearly scaled with the lattice strain for both pristine and subsurface carbon atom-modified $\operatorname{Pd}(111)$ surfaces, except for the adsorption of $\mathrm{C}_{2} \mathrm{H}_{2}$ over $\mathrm{Pd}(111)$-C. The activity for ethylene formation typically corresponds to the region of strong reactants adsorption in the volcano curve; such an effect of lattice strain and the presence of subsurface promoters can improve the activity of the catalyst through the weakening of the adsorption of reactants. The activity and selectivity for $\operatorname{Pd}(111)-\mathrm{C}$ are always higher than those for the pristine $\operatorname{Pd}(111)$ surfaces with respect to ethylene formation. Based on the results obtained, Pd-based catalysts with shrinking lattice constants are suggested as good candidates for the selective hydrogenation of acetylene. A similar approach can be used to facilitate the future design of novel heterogeneous catalysts.
\end{abstract}

(C) 2018, Dalian Institute of Chemical Physics, Chinese Academy of Sciences. Published by Elsevier B.V. All rights reserved.

\section{Introduction}

Selective hydrogenation of organic compounds such as unsaturated hydrocarbons, $\alpha, \beta$-unsaturated aldehydes (ketones), and aromatic nitro-compounds over catalysts is an interesting research area in heterogeneous catalysis and has been attracting increasing attention for a long time [1-9]. The current focus in this research area is to achieve high selectivity for relatively unstable intermediates; this requires that the hydrogenation only takes place for the proper bonds, and further hydrogenation should be prevented in some cases. The key aspect to solving this problem is to develop a proper catalyst exhibiting a high selectivity as well as high activity.

Selective hydrogenation of acetylene in ethylene feed is very important in the olefin industry, as acetylene acts as an impurity in the olefin feed that poisons the catalysts used subsequently for the polymerization of ethylene. The selective hydrogenation of acetylene will both remove this impurity and increase the amount of ethylene produced. The most effective catalyst for this reaction was found to be Pd-based owing to its relatively high selectivity and favorable activity. Previous investigations found that the presence of subsurface species such

\footnotetext{
* Corresponding author. Tel: +86-21-20685147; E-mail: yangbo1@shanghaitech.edu.cn

This work was supported by the National Natural Science Foundation of China (21603142), the Shanghai Pujiang Program (16PJ1406800) and the Shanghai Young Eastern Scholar Program (QD2016049).

DOI: 10.1016/S1872-2067(18)63081-5 | http://www.sciencedirect.com/science/journal/18722067 | Chin. J. Catal., Vol. 39, No. 9, September 2018
} 
as carbon atoms formed from the dissociation of reactants and reaction intermediates could significantly promote the selective hydrogenation of acetylene over Pd $[10,11]$. Our previous density functional theory (DFT) calculations revealed that subsurface species could promote the reaction through the electronic modification effect, and the adsorption energy of alkenes over Pd surfaces would be decreased, thereby inhibiting the possibility of over-hydrogenation reactions [12-16].

It was widely reported in the literature that the surface strain effect could influence the reactivity of metal surfaces and that the adsorption properties could be varied by changing the metal lattice size [9,17-37]. Nørskov and co-workers found using DFT calculations that the surface reactivity of $\mathrm{Ru}(0001)$ towards the adsorption of carbon/oxygen and the dissociation of CO increased with lattice expansion. They further correlated the increased reactivity with the observed upshift in the metal $d$ states during lattice expansion, and concluded that surface strain can be used to tailor the catalytic activities of metals [18]. Such a $d$-band-centric argument has been widely accepted by the catalysis community. A further study carried out by Mavrikakis' group demonstrated that such lattice strains could induce the formation of subsurface species in some cases [20]. The authors employed hydrogen adsorption at the subsurface sites of $\mathrm{Ni}(111)$ as an example, and found that subsurface hydrogen would form more readily in stretched regions than in the unstretched regions of the Ni surface.

Experimentally engineering the strain of catalyst surfaces has been attracting increased attention recently to tune the performance of these catalysts. However, the catalytic systems are far more complex, with many more variables to consider. One of the examples is that the surface of Pd during acetylene hydrogenation might be carbide-like, and therefore, the adsorption process could be influenced by both the surface strain and presence of subsurface species. Meanwhile, the direct relationship between the surface strain and the selectivity and activity for acetylene hydrogenation over Pd under the reaction conditions is still missing, which is the focus of the current work.

\section{Computational details}

All the DFT calculations in this work were performed with the VASP [38-41] code in the slab models. The exchange-correlation functional PW91 [42] was used to calculate the electronic structure with generalized gradient approximation (GGA). The projector augmented wave (PAW) method was employed to describe the interactions between the atomic cores and electrons [43,44]. For all the Pd-based surfaces, four-layer $2 \times 2$ slabs with the upmost two layers relaxed during optimization were used to model the adsorption and reaction processes. The optimized equilibrium lattice constant was 3.95 $\AA$ [12], which is close to the experimentally measured $3.89 \AA$. Then, we changed the lattice constant by minus or plus one, two, or four percent, which are designated as $\mathrm{m} 1 \mathrm{p}, \mathrm{m} 2 \mathrm{p}, \mathrm{m} 4 \mathrm{p}$, p1p, p2p and p4p. A $5 \times 5 \times 1 k$-point sampling in the surface Brillouin zone was used in all the calculations. The vacuum height was set to be more than $12 \AA$ to avoid any interactions between the slabs. An energy cutoff of $500 \mathrm{eV}$ and a force threshold on each relaxed atom of $0.05 \mathrm{eV} / \AA$ A were used in the current work. The transition states were located using the constrained minimization method [45-47], and only one imaginary frequency was found for the transition states obtained. The adsorption and binding energies are defined as follows:

$$
E_{\text {ad }}=E_{\text {total }}-\left(E_{\mathrm{g}}+E_{\text {slab }}\right) \text {, }
$$

where $E_{\text {total }}$ is the energy of the system after adsorption, $E_{\mathrm{g}}$ denotes the energy of the gas-phase adsorbate, and $E_{\text {slab }}$ is the energy of the slab. For the adsorption energy of the hydrogen atom, we used the energy of $1 / 2 \mathrm{H}_{2}$ as the reference.

In this work, we used the simulation package CatMAP developed by Nørskov's group, which has been proven to be a powerful tool in predicting catalytic trends, to perform the microkinetic analyses of the hydrogenation activity $[48,49]$. In our calculations, the reaction conditions were set as: $T=350 \mathrm{~K}$, $P_{\mathrm{C}_{2} \mathrm{H}_{2}}=1$ bar, $P_{\mathrm{H}_{2}}=10$ bar, and $P_{\mathrm{C}_{2} \mathrm{H}_{4}}=0.01$ bar. We used the "fixed_entropy_gas" and "frozen_adsorbate" models to deal with the thermochemistry of the gases and adsorbates by assuming that the entropy of all gases is $0.002 \mathrm{eV} / \mathrm{K}$, except that of $\mathrm{H}_{2}(0.00135 \mathrm{eV} / \mathrm{K})$.

\section{Results and discussion}

The energies corresponding to the adsorption of $\mathrm{C}_{2} \mathrm{H}_{2}, \mathrm{H}$, and $\mathrm{C}_{2} \mathrm{H}_{4}$ over pristine $\mathrm{Pd}(111)$ surfaces as a function of the variation in the lattice strain of Pd can be found in Fig. 1. It can be observed that the adsorption energies of all three species correlate linearly with the lattice strain, and a larger lattice results in stronger adsorption in all the cases; this is consistent with the $d$-band center theory and the results presented by Mavrikakis et al. [18]. The optimized adsorption configurations of $\mathrm{C}_{2} \mathrm{H}_{2}, \mathrm{C}_{2} \mathrm{H}_{3}$, and $\mathrm{C}_{2} \mathrm{H}_{4}$, as well as the transition state structures for the hydrogenation of these $\mathrm{C}_{2}$ species over $\mathrm{m} 1 \mathrm{p} \mathrm{Pd}(111)$ are shown in Fig. S1 (Supporting Information, SI) as examples.

Based on the linear relationships between the adsorption

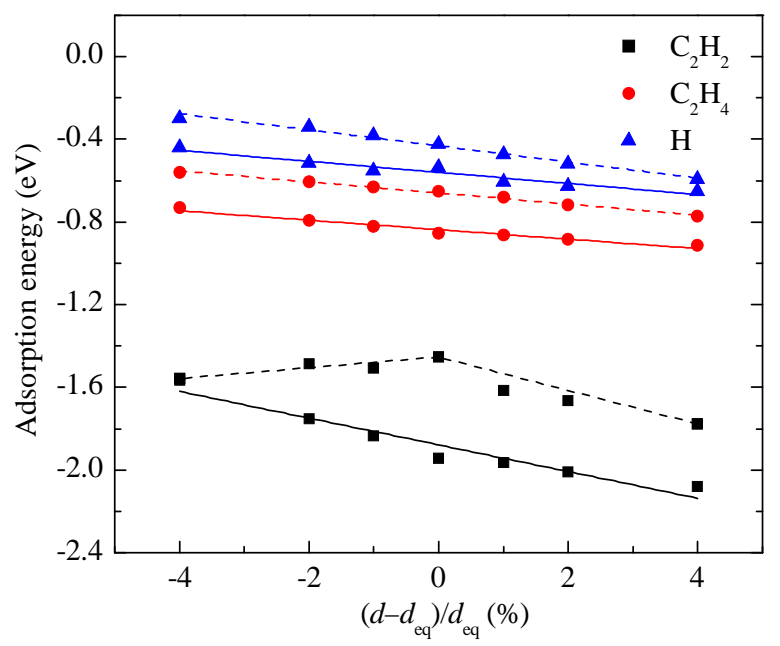

Fig. 1. Adsorption energies of acetylene, ethylene, and hydrogen over pristine (solid lines) and subsurface carbon modified (dashed lines) $\operatorname{Pd}(111)$ as functions of the lattice strain. Here, $d$ and $d_{\text {eq }}$ represent the varied and equilibrium lattice constants, respectively, and this notation has been used throughout the paper. 

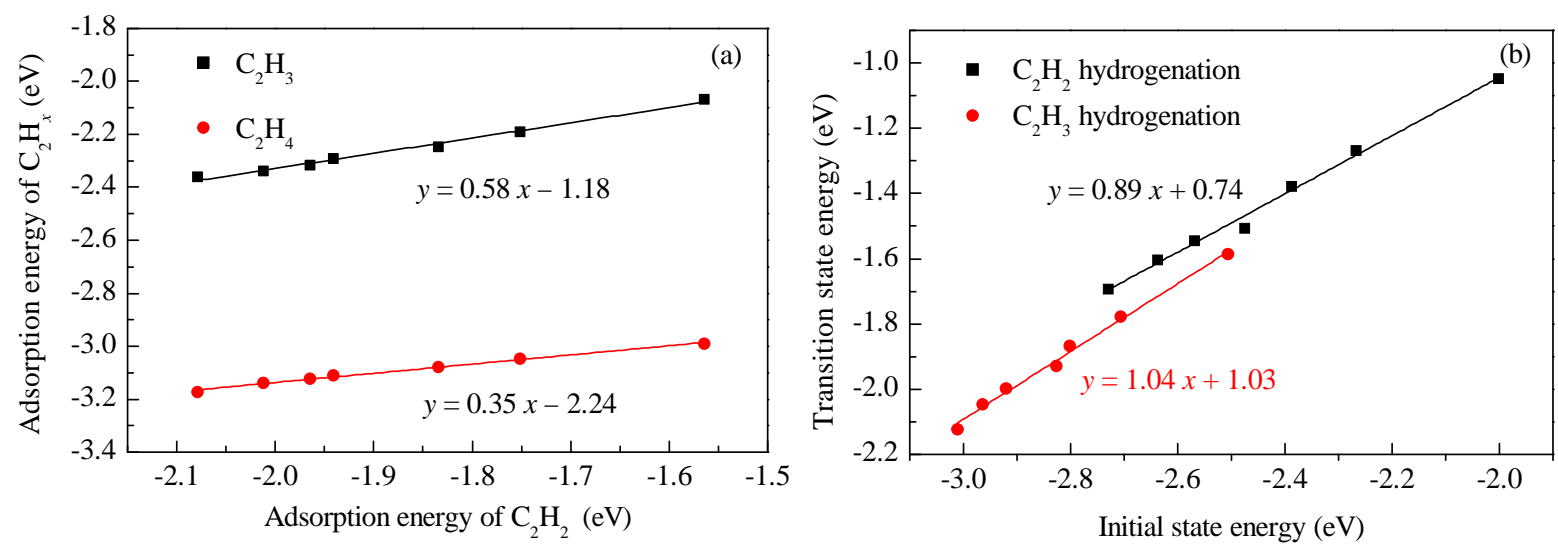

Fig. 2. Scaling relationships for the adsorption energies calculated for pristine $\operatorname{Pd}(111)$ surfaces with different strains. (a) Scaling relationship for the adsorption energies of $\mathrm{C}_{2} \mathrm{H}_{3}$ and $\mathrm{C}_{2} \mathrm{H}_{4}$ as a function of the adsorption energy of $\mathrm{C}_{2} \mathrm{H}_{2}$. (b) Transition state scaling relationship for the elementary reactions involved in the hydrogenation of $\mathrm{C}_{2} \mathrm{H}_{2}$ to $\mathrm{C}_{2} \mathrm{H}_{3}$ and further hydrogenation of $\mathrm{C}_{2} \mathrm{H}_{3}$ to $\mathrm{C}_{2} \mathrm{H}_{4}$. Here, the transition state energies are plotted against the corresponding initial state energies of the elementary reactions.

energies and lattice strain, the scaling relationship between the adsorption energies can be established using the adsorption energy of $\mathrm{C}_{2} \mathrm{H}_{2}$ and $\mathrm{H}$ as descriptors; this is shown in Fig. 2. It is found that the transition state (TS) energies are also linearly correlated with the corresponding initial state (IS) energies for the elementary steps involved in the hydrogenation of $\mathrm{C}_{2} \mathrm{H}_{2}$ to $\mathrm{C}_{2} \mathrm{H}_{4}$ over $\mathrm{Pd}(111)$ surfaces with different strains. All the TS-IS scaling relations are also presented in Fig. 2. The corresponding activation barriers and reaction energies of the elementary reaction steps involved in the hydrogenation of acetylene to ethylene over the pristine $\mathrm{Pd}(111)$ surfaces with different lattice constants can be found in Table S1.

Combining all the scaling relationships in Fig. 2 and using the microkinetic modeling approach developed by Nørskov's group [48,50,51], a three-dimensional activity map can be obtained for the formation of ethylene, as shown in Fig. 3. It can be seen that although smaller lattice constants result in weaker adsorption of the reactants over the pristine Pd(111) surfaces, the activity for ethylene formation is increased. This may be

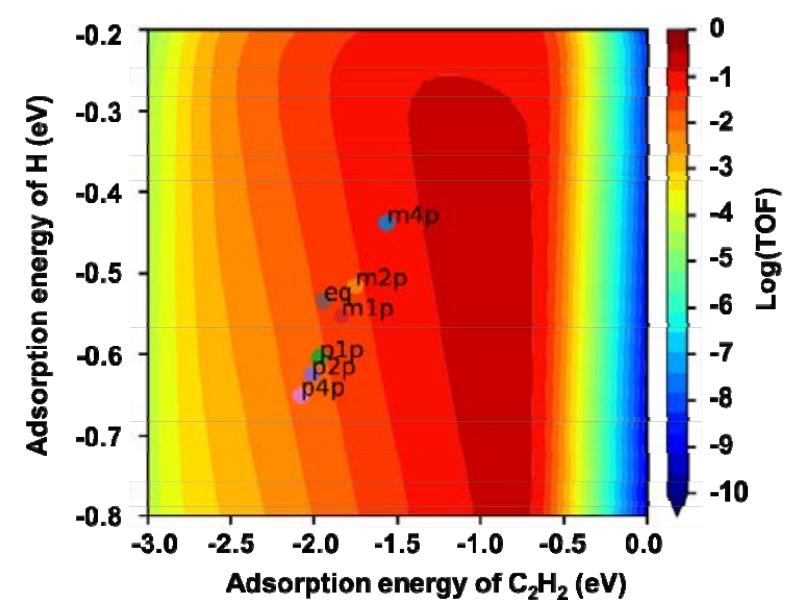

Fig. 3. Activity for ethylene formation as a function of the adsorption energy of $\mathrm{H}$ and $\mathrm{C}_{2} \mathrm{H}_{2}$ over different surfaces. mip (pip) are the $\mathrm{Pd}(111)$ surfaces with $\mathrm{i} \%$ smaller (larger) lattice, and eq represents the $\operatorname{Pd}(111)$ surface with the equilibrium lattice constant. This notation is used throughout the paper. due to the fact that the activity of $\operatorname{Pd}(111)$ for the hydrogenation of acetylene to ethylene corresponds to the strong adsorption side of the volcano curve, where, in general, the desorption of products from the surface is the rate-determining step [52]. On the other hand, weakening of the adsorption strength of the surface species will increase the turnover rate by facilitating the desorption process, which is similar to the case of Ni-catalyzed acetylene hydrogenation that we reported previously [53].

In order to further investigate the possible formation of subsurface species, we calculated the average adsorption energies of carbon and hydrogen atoms at the subsurface sites of $\operatorname{Pd}(111)$ surfaces with different lattice constants and subsurface coverages, and the corresponding trends are presented in Fig. 4. There are typically two possible sites for the adsorption of carbon and hydrogen at the subsurface site of $\operatorname{Pd}(111)$, namely, the subsurface octahedral and tetrahedral sites; the energies shown in Fig. 4 are those with lower energies at one site than the other. It is clearly demonstrated in this figure that the adsorption energies of both carbon and hydrogen become less negative with decreasing lattice constants, which is similar to the results reported by Greeley et al. [20]. However, the variation in the adsorption energies as a function of subsurface coverage is different between the carbon and hydrogen atoms. For carbon atoms, the adsorption becomes weaker with the increase in the subsurface coverages, while the adsorption strength of hydrogen does not vary much for different coverages. This observation is consistent with those that we reported recently for both $\operatorname{Pd}(111)$ and $\operatorname{Pd}(100)$ surfaces [12,15]. It should be mentioned that when the lattice of $\mathrm{Pd}$ is expanded by $4 \%$ compared to the equilibrated Pd lattice (p4p), the adsorption of subsurface hydrogen at the octahedral/tetrahedral sites becomes unstable, and these hydrogen atoms diffuse to the corresponding surface fcc/hcp sites after structural optimization (Fig. S2); therefore the corresponding adsorption energies are not included in Fig. 4.

Here, we further consider Pd(111) surfaces with 0.25 monolayer (ML) subsurface carbon coverage, named $\mathrm{Pd}(111)-\mathrm{C}$, as an example to investigate the effect of the presence of subsur- 

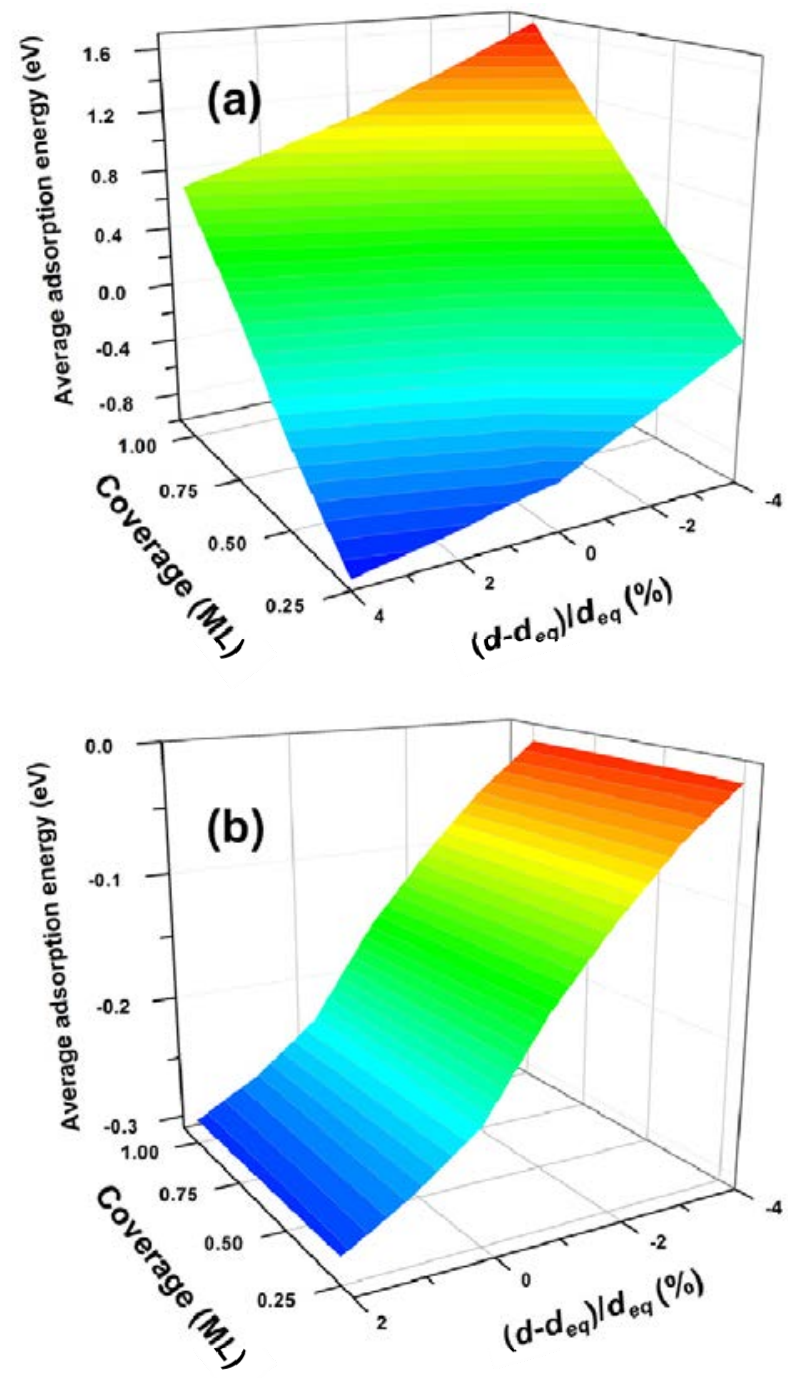

Fig. 4. Average adsorption energy of carbon (a) and hydrogen (b) at the subsurface site as a function of lattice strain and coverage. These energies are referenced to the energy of $\left(\mathrm{C}_{2} \mathrm{H}_{2}-\mathrm{H}_{2}\right) / 2$ and ${ }_{1}^{1}{ }_{2} \mathrm{H}_{2}$ for the carbon and hydrogen atom, respectively.

face atoms on the catalytic reactivity. The adsorption energies of $\mathrm{C}_{2} \mathrm{H}_{2}, \mathrm{H}$, and $\mathrm{C}_{2} \mathrm{H}_{4}$ are calculated over $\mathrm{Pd}(111)-\mathrm{C}$ and plotted as a function of the lattice strain in Fig. 1. In general, the adsorption of all the species over the Pd(111) surfaces become weaker upon the formation of subsurface carbon atoms. In our previous work, we found that the weakened adsorption over Pd(111)-C than over Pd(111) was due to the downshift of the metal $d$ band upon the adsorption of carbon atoms at the subsurface sites [12]. We also find that the adsorption energies of $\mathrm{H}$ and $\mathrm{C}_{2} \mathrm{H}_{4}$ still linearly scale with the lattice strain, while the adsorption trend of $\mathrm{C}_{2} \mathrm{H}_{2}$ shows a peak at the equilibrium constant, indicating that changing the lattice constants of $\operatorname{Pd}(111)-C$ from those of the equilibrated lattice will always result in stronger acetylene adsorption over the surface. After carefully examining the adsorption energies of $\mathrm{C}_{2} \mathrm{H}_{2}$ over all the $\mathrm{Pd}(111)-\mathrm{C}$ surfaces investigated, we found that the trend for larger lattice constants was the same as those observed for other species, while a smaller lattice would give rise to stronger adsorption, resulting in a stronger deviation from the linear trend. This is believed to result from the slightly deformed $\operatorname{Pd}(111)-C$ surface with smaller lattice constants due to the strong adsorption of $\mathrm{C}_{2} \mathrm{H}_{2}$, as shown in Fig. S3; such deformation will effectively release the stress within the lattice and lower the energy of the system. A similar deformation is not observed for the adsorption of $\mathrm{C}_{2} \mathrm{H}_{4}$ over $\mathrm{Pd}(111)$ - $\mathrm{C}$ surfaces, which involve weaker binding than $\mathrm{C}_{2} \mathrm{H}_{2}$. Nevertheless, it will be shown later that such unusual adsorption behavior of acetylene observed still supports our argument on the trend for the catalytic activity for ethylene formation.

Subsequently, the activity for ethylene formation is calculated based on all the activation energies and reaction energies obtained for all the surfaces studied, and the selectivity is also estimated by comparing the differences between the hydrogenation and desorption barriers of ethylene over the different catalyst surfaces, which is defined as $\Delta E_{\mathrm{a}}=E_{\mathrm{a} \text {,hydr }}-E_{\mathrm{a} \text {,des. }}$ All of the energies are listed in the tables of the SI. According to our previous work [12,15,54-56], desorption barriers can be estimated based on the absolute value of the corresponding adsorption energies of ethylene, and therefore, higher $\Delta E_{\text {a values }}$ result in higher ethylene selectivity.

All the values of $\Delta E_{\mathrm{a}}$ and $\log$ (TOF) are shown in Fig. 5, and the following trends can be readily observed.

(1) $\Delta E_{\mathrm{a}}$ is always positive for both the pristine and subsurface carbon modified Pd(111) surfaces studied, indicating that
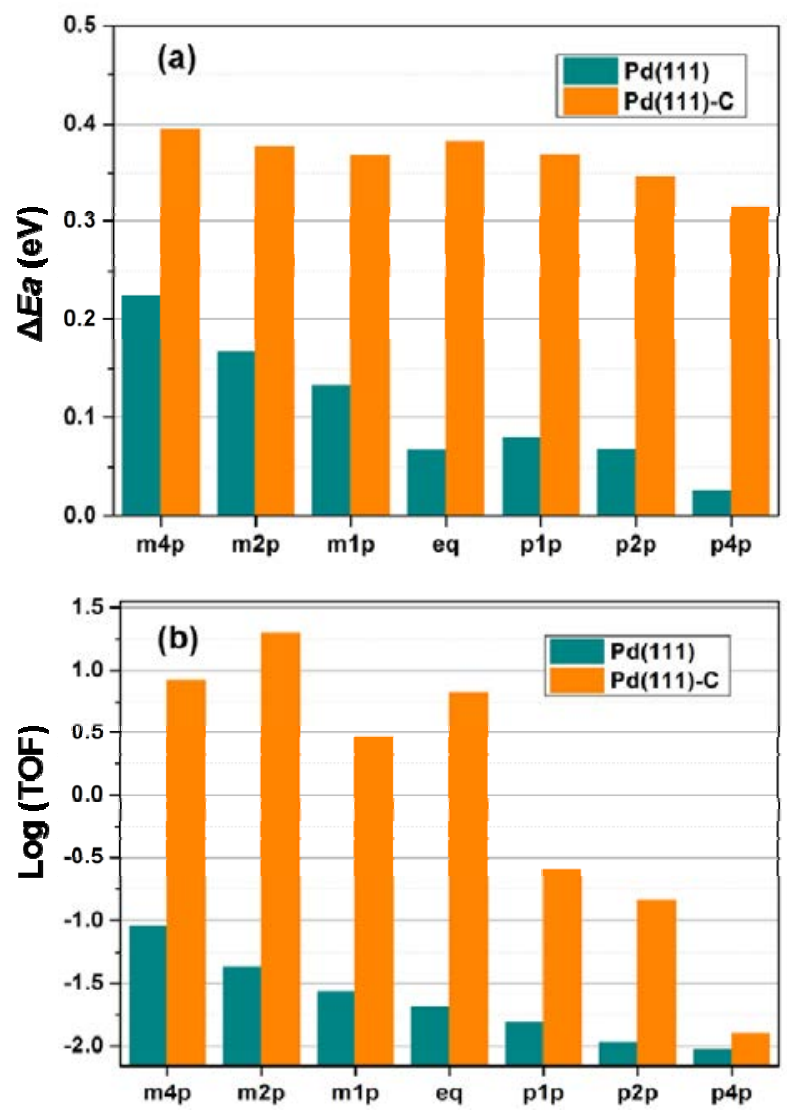

Fig. 5. Selectivity (a) and activity (b) for ethylene formation over pristine and subsurface carbon modified $\operatorname{Pd}(111)$ surfaces with varying lattice strain. 
the desorption of ethylene from the catalyst surface is preferred for all the surfaces studied;

(2) The activity and selectivity of ethylene over $\mathrm{Pd}(111)-\mathrm{C}$ is always higher than those of the corresponding pristine $\operatorname{Pd}(111)$. It is found from the tables in the SI that the increased ethylene selectivity upon subsurface carbon modification is mainly due to the weakened adsorption of ethylene over these surfaces;

(3) Decreasing the lattice constant will improve the activity and selectivity, in general, for ethylene formation over pristine Pd(111);

(4) The m4p and $m 2 p$ catalysts with subsurface carbon, which are the Pd(111)-C surfaces with four and two percent smaller lattice constants than the equilibrated Pd lattice, reveal higher selectivity and activity for ethylene formation from acetylene hydrogenation than the normal Pd(111) and other Pd(111)-C surfaces.

As revealed above, the adsorption of acetylene over pristine $\operatorname{Pd}(111)$ is on the strong adsorption side of the volcano curve for ethylene formation; the enhancement in the activity for ethylene formation can be rationalized by the weaker adsorption of the reactants over the $\mathrm{Pd}(111)-\mathrm{C}$ surfaces. However, upon the formation of the subsurface carbon atoms, no clear trend can be observed in the activities of the Pd(111)-C surfaces with smaller lattice constants than the equilibrated value (i.e., $m 4 p, m 2 p$, and $m 1 p \operatorname{Pd}(111)-C$ surfaces) with the variation in the lattice constant. We ascribe this to the unusual scaling relation shown in Fig. 1, where a peak is observed in the trend of the acetylene adsorption energies over the subsurface carbon modified Pd(111) surfaces. Interestingly, we found that when the $\log (\mathrm{TOF})$ over $\mathrm{Pd}(111)$-C surfaces were plotted as a function of the adsorption energy of $\mathrm{C}_{2} \mathrm{H}_{2}+\mathrm{H}$, a linear relationship was obtained (Fig. S4); such a relationship further supports our argument that the adsorption energy of the reactants corresponds to the strong adsorption side of the volcano curve for ethylene formation.

It is clearly shown in the current work that the effects of lattice strain and subsurface promoters can improve the performance of catalysts in the case of Pd-catalyzed selective hydrogenation of acetylene. Although the activity of $m 2 p \operatorname{Pd}(111)-C$ is the highest, its selectivity for ethylene formation is slightly lower than the m4p Pd(111)-C catalyst, and we consider the latter as a good candidate for the selective acetylene hydrogenation reaction. Such shrinking of the lattice can be achieved experimentally through a number of catalyst preparation methods, as reported in the literature, including constructing core/shell type M/Pd structures, where $\mathrm{M}$ has a slightly smaller lattice constant than $\mathrm{Pd}$, synthesizing Pd nanowires or octahedron nanoparticles with the first-shell Pd-Pd bond length possibly shorter than that of the Pd foil, or producing crystal twinning during the Pd catalyst synthesis process, wherein a lattice strain may result from the mismatch between the twinned structures [34-36,57,58].

\section{Conclusions}

We have thoroughly examined the effects of lattice strain and subsurface promoters, which are both important issues in heterogeneous catalysis, on the catalytic selectivity and activity of Pd by considering the selective hydrogenation of acetylene as an example. It is found that the adsorption energies of the reactants and products are, in general, linearly scaled with the lattice strain for both pristine and subsurface carbon atom modified $\mathrm{Pd}(111)$ surfaces, except for the adsorption of $\mathrm{C}_{2} \mathrm{H}_{2}$ over $\mathrm{Pd}(111)-\mathrm{C}$. The activity for ethylene formation corresponds to the strong reactant adsorption side of the volcano curve, and such lattice strain effects and presence of subsurface promoters can improve the activity of the catalyst through the weakening of the adsorption of reactants. The activity and selectivity of Pd(111)-C are always higher than those of the pristine Pd(111) surfaces for ethylene formation. These Pd-based catalysts are suggested as good candidates based on the framework that we have developed for the selective hydrogenation of acetylene, and a similar approach can be used to facilitate the future design of novel heterogeneous catalysts.

\section{Acknowledgments}

We thank the HPC Platform of ShanghaiTech University for computing time.

\section{References}

[1] A. Borodziński, G. C. Bond, Catal. Rev. Sci. Eng., 2006, 48, 91-144.

[2] A. Borodziński, G. C. Bond, Catal. Rev. Sci. Eng., 2008, 50, 379-469.

[3] P. Gallezot, D. Richard, Catal. Rev. Sci. Eng., 1998, 40, 81-126.

[4] B. Yang, D. Wang, X. Q. Gong, P. Hu, Phys. Chem. Chem. Phys., 2011, 13, 21146-21152.

[5] H. G. Manyar, R. Morgan, K. Morgan, B. Yang, P. Hu, J. Szlachetko, J. Sa, C. Hardacre, Catal. Sci. Technol., 2013, 3, 1497-1500.

[6] H. G. Manyar, B. Yang, H. Daly, H. Moor, S. McMonagle, Y. Tao, G. D. Yadav, A. Goguet, P. Hu, C. Hardacre, ChemCatChem, 2013, 5, 506-512.

[7] Y. Gu, Y. H. Zhao, P. P. Wu, B. Yang, N. T. Yang, Y. Zhu, Nanoscale, 2016, 8, 10896-10901.

[8] K. L. Wang, B. Yang, Catal. Sci. Technol., 2017, 7, 4024-4033.

[9] J. J. Mao, W. X. Chen, W. M. Sun, Z. Chen, J. J. Pei, D. S. He, C. L. Lv, D. S. Wang, Y. D. Li, Angew. Chem. Int. Ed., 2017, 56, 11971-11975.

[10] D. Teschner, J. Borsodi, A. Wootsch, Z. Révay, M. Hävecker, A. Knop-Gericke, S. D. Jackson, R. Schlögl, Science, 2008, 320, 86-89.

[11] F. Studt, F. Abild-Pedersen, T. Bligaard, R. Z. Sørensen, C. H. Christensen, J. K. Nørskov, Angew. Chem. Int. Ed., 2008, 47, 9299-9302.

[12] B. Yang, R. Burch, C. Hardacre, G. Headdock, P. Hu, J. Catal., 2013, 305, 264-276.

[13] B. Yang, R. Burch, C. Hardacre, P. Hu, P. Hughes, J. Phys. Chem. C, 2014, 118, 3664-3671.

[14] B. Yang, R. Burch, C. Hardacre, P. Hu, P. Hughes, J. Phys. Chem. C, 2014, 118, 1560-1567.

[15] B. Yang, R. Burch, C. Hardacre, P. Hu, P. Hughes, Surf. Sci., 2016, 46, $45-49$.

[16] P. P. Wu, B. Yang, Phys. Chem. Chem. Phys., 2016, 18, 21720-21729.

[17] M. Gsell, P. Jakob, D. Menzel, Science, 1998, 280, 717-720. 


\section{Graphical Abstract}

Chin. J. Catal., 2018, 39: 1493-1499 doi: 10.1016/S1872-2067(18)63081-5

Influence of surface strain on activity and selectivity of Pd-based catalysts for the hydrogenation of acetylene: A DFT study

Ping Wang, Bo Yang*

ShanghaiTech University

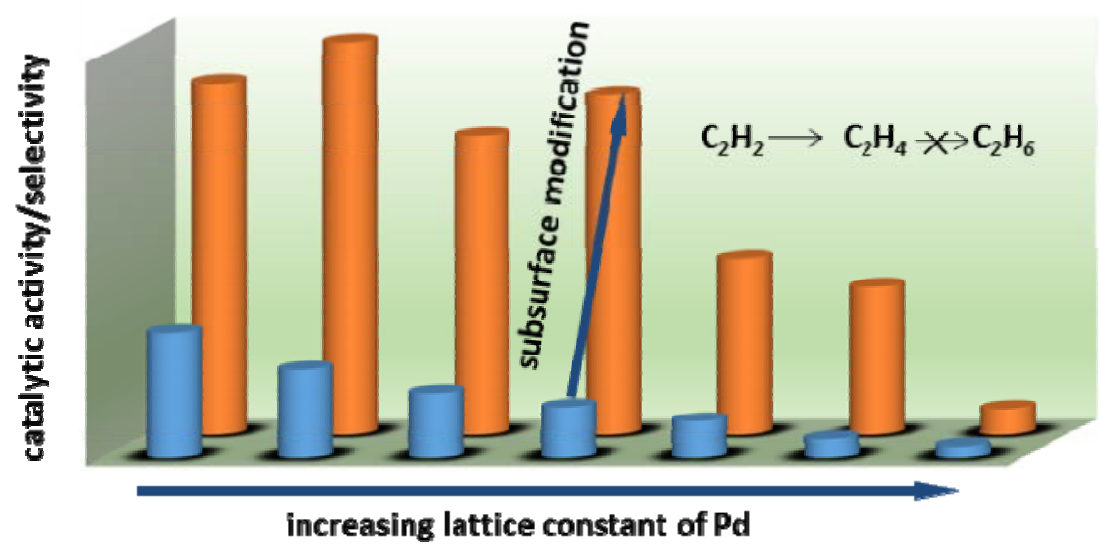

The effect of surface strain on the activity and selectivity of Pd and Pd-carbide for the hydrogenation of acetylene is thoroughly examined.

[18] M. Mavrikakis, B. Hammer, J. K. Nørskov, Phys. Rev. Lett., 1998, 81, 2819-2822.

[19] A. Schlapka, M. Lischka, A. Gross, U. Kasberger, P. Jakob, Phys. Rev. Lett., 2003, 91, 016101/1-016101/4.

[20] J. Greeley, W.R. Krekelberg, M. Mavrikakis, Angew. Chem. Int. Ed., 2004, 43, 4296-4300.

[21] L. A. Kibler, A. M. El-Aziz, R. Hoyer, D. M. Kolb, Angew. Chem. Int. Ed., 2005, 44, 2080-2084.

[22] P. Strasser, S. Koh, T. Anniyev, J. Greeley, K. More, C. F. Yu, Z. C. Liu, S. Kaya, D. Nordlund, H. Ogasawara, M. F. Toney, A. Nilsson, Nat. Chem., 2010, 2, 454-460.

[23] J. B. Wu, P. P. Li, Y. T. Pan, S. Warren, X. Yin, H. Yang, Chem. Soc. Rev., 2012, 41, 8066-8074.

[24] X. M. Wang, Y. Orikasa, Y. Takesue, H. Inoue, M. Nakamura, T. Minato, N. Hoshi, Y. Uchimoto, J. Am. Chem. Soc., 2013, 135, 5938-5941.

[25] I. Goikoetxea, J. I. Juaristi, R. D. Muino, M. Alducin, Phys. Rev. Lett., 2014, 113, 066103/1-066103/5.

[26] S. Zhang, X. Zhang, G. M. Jiang, H. Y. Zhu, S. J. Guo, D. Su, G. Lu, S. H. Sun, J. Am. Chem. Soc., 2014, 136, 7734-7739.

[27] Q. B. Deng, V. Gopal, J. Weissmuller, Angew. Chem. Int. Ed., 2015, 54, 12981-12985.

[28] M. S. Du, L. S. Cui, Y. Cao, A. J. Bard, J. Am. Chem. Soc., 2015, 137, 7397-7403.

[29] L. Li, F. Abild-Pedersen, J. Greeley, J. K. Nørskov, J. Phys. Chem. Lett., 2015, 6, 3797-3801.

[30] B. T. Sneed, A. P. Young, C. K. Tsung, Nanoscale, 2015, 7, 12248-12265.

[31] M. F. Francis, W. A. Curtin, Nat. Commun., 2015, 6, 6261.

[32] S. E. Temmel, E. Fabbri, D. Pergolesi, T. Lippert, T. J. Schmidt, ACS Catal., 2016, 6, 7566-7576.

[33] K. Yan, T. A. Maark, A. Khorshidi, V. A. Sethuraman, A. A. Peterson,
P. R. Guduru, Angew. Chem. Int. Ed., 2016, 55, 6175-6181.

[34] C. H. Kuo, L. K. Lamontagne, C. N. Brodsky, L. Y. Chou, J. Zhuang, B. T. Sneed, M. K. Sheehan, C. K. Tsung, ChemSusChem, 2013, 6, 1993-2000.

[35] M. F. Li, Z. P. Zhao, T. Cheng, A. Fortunelli, C. Y. Chen, R. Yu, Q. H. Zhang, L. Gu, B. V. Merinov, Z. Y. Lin, E. B. Zhu, T. Yu, Q. Y. Jia, J. H. Guo, L. Zhang, W. A. Goddard, Y. Huang, X. F. Duan, Science, 2016, 354, 1414-1419.

[36] H. W. Huang, H. H. Jia, Z. Liu, P. F. Gao, J. T. Zhao, Z. L. Luo, J. L. Yang, J. Zeng, Angew. Chem. Int. Ed., 2017, 56, 3594-3598.

[37] X. H. Bao, Acta Phys. Chim. Sin., 2017, 33, 651-652.

[38] G. Kresse, J. Hafner, Phys. Rev. B, 1993, 47, 558-561.

[39] G. Kresse, J. Hafner, Phys. Rev. B, 1994, 49, 14251-14269.

[40] G. Kresse, J. Furthmuller, Comput. Mater. Sci., 1996, 6, 15-50.

[41] G. Kresse, J. Furthmuller, Phys. Rev. B, 1996, 54, 11169-11186.

[42] J. P. Perdew, Y. Wang, Phys. Rev. B, 1992, 45, 13244-13249.

[43] P. E. Blöchl, Phys. Rev. B, 1994, 50, 17953-17979.

[44] G. Kresse, D. Joubert, Phys. Rev. B, 1999, 59, 1758-1775.

[45] A. Alavi, P. Hu, T. Deutsch, P. L. Silvestrelli, J. Hutter, Phys. Rev. Lett., 1998, 80, 3650-3653.

[46] Z. P. Liu, P. Hu, J. Am. Chem. Soc., 2003, 125, 1958-1967.

[47] A. Michaelides, P. Hu, J. Am. Chem. Soc., 2001, 123, 4235-4242.

[48] A. J. Medford, C. Shi, M. J. Hoffmann, A. C. Lausche, S. R. Fitzgibbon, T. Bligaard, J. K. Nørskov, Catal. Lett., 2015, 145, 794-807.

[49] P. P. Wu, B. Yang, ACS Catal., 2017, 7, 7187-7195.

[50] N. Y. Yang, A. J. Medford, X. Y. Liu, F. Studt, T. Bligaard, S. F. Bent, J. K. Nørskov, J. Am. Chem. Soc., 2016, 138, 3705-3714.

[51] A. A. Latimer, A. R. Kulkarni, H. Aljama, J. H. Montoya, J. S. Yoo, C. Tsai, F. Abild-Pedersen, F. Studt, J. K. Nørskov, Nat. Mater., 2017, $16,225-229$.

[52] B. Yang, R. Burch, C. Hardacre, G. Headdock, P. Hu, ACS Catal., 2014, 4, 182-186. 
[53] B. Yang, R. Burch, C. Hardacre, G. Headdock, P. Hu, ACS Catal,, 2012, 2, 1027-1032.

[54] B. Yang, X. Q. Gong, H. F. Wang, X. M. Cao, J. J. Rooney, P. Hu, J. Am. Chem. Soc., 2013, 135, 15244-15250.

[55] B. Yang, R. Burch, C. Hardacre, P. Hu, P. Hughes, Catal. Sci. Technol., 2017, 7, 1508-1514.
[56] K. Yang, B. Yang, Phys. Chem. Chem. Phys., 2017, 19, 18010-18017.

[57] A. X. Yin, X. Q. Min, W. Zhu, H. S. Wu, Y. W. Zhang, C. H. Yan, Chem. Commun., 2012, 48, 543-545.

[58] J. Wu, L. Qi, H. You, A. Gross, J. Li, H. Yang, J. Am. Chem. Soc., 2012, $134,11880-11883$.

\title{
密度泛函理论计算研究表面应力对钯催化乙炔选择性加氢活性与选择性的影响
}

\author{
王 萍, 杨 波 ${ }^{*}$ \\ 上海科技大学物质科学与技术学院, 上海 201210
}

\begin{abstract}
摘要: 在石油催化裂解过程中, 除了生成乙烯、丙烯及丁烯等烯烃, 还会产生部分炔烃. 目前工业上通常采用炔烃选择性加 氢转化为对应的单烯烃, 以除去其中炔烃. 由于产品烯烃中的炔烃等杂质含量需极低, 这就对用于加氢催化剂的活性和选 择性提出了很高的要求, 即催化剂需要选择性吸附炔烃并加氢, 而不损失其中的烯烃. 经过前期大量的基础研究工作, 目 前工业中炔烃选择性加氢应用最广泛的催化剂是负载型钯基催化剂. 然而, 单独的钯金属选择性并不理想, 因而对其选择 性以及活性进行调控成为了当前关注的研究课题.

本文采用密度泛函理论计算结合微观反应动力学模拟手段, 研究了钯金属表面应力存在条件下的活性与选择性, 以及 形成次表层物种的可能性和形成后的活性与选择性. 研究发现, 改变钯金属的晶格参数与表面应力, 反应物、表面反应中 间体和产物的吸附能都会产生相应的变化, 且吸附能与晶格参数的变化存在线性关系, 晶格参数越大, 吸附越强. 利用表 面反应过渡态能量与初始态能量之间的线性关系, 相应的乙炔加氢生成乙烯的反应速率可以通过微观反应动力学模拟得 到. 结果显示, 不同晶格参数的钯催化剂催化乙炔加氢生成乙烯的反应活性位于相应火山型曲线的强吸附侧, 即减弱乙炔 和氢的吸附强度可提高乙烯的生成速率. 在此基础上, 本文研究了不同表面应力的钯催化剂在次表面吸附不同覆盖度碳 原子和氢原子的情况, 发现晶格参数越大越有利于碳原子和氢原子在次表面的吸附. 同时, 研究发现在次表面碳掺杂的条 件下, 不同表面应力条件下的钯催化剂的活性均有所增强. 此外, 由于乙烯在所有研究的钯催化剂表面脱附比进一步加氢 容易, 因而乙烯都可以选择性生成.
\end{abstract}

关键词: 表面应力; 钯; 乙炔加氢; 选择性; 活性; 次表面; 密度泛函理论; 微观反应动力学模拟

收稿日期: 2018-03-01. 接受日期: 2018-04-07. 出版日期: 2018-09-05.

*通讯联系人. 电话: (021)20685147; 电子信箱: yangbo1@shanghaitech.edu.cn

基金来源: 国家自然科学基金 (21603142); 上海浦江人才计划 (16PJ1406800); 上海高校青年东方学者 (QD2016049).

本文的电子版全文由Elsevier出版社在ScienceDirect上出版(http://www.sciencedirect.com/science/journal/18722067). 